ANL- 6913

Chemistry

(TID-4500, 32nd Ed.)

AEC Research and

Development Report

ARGONNE NATIONAL LABORATORY

9700 South Cass Avenue

Argonne, Illinois 60440

\title{
APPLICATION OF THE VACUUM-CUP TECHNIQUE \\ TOWARD SPECTROCHEMICAL ANALYSIS \\ OF URANIUM-FISSIUM ALLOY
}

by

Yu Yokoyama* and John P. Faris

Chemistry Division

*Present Address: Atomic Fuel Corporation, Tokai-Mura, Ibaraki-Ken, Japan

July 1964

Operated by The University of Chicago

under

Contract W-31-109-eng-38

with the

U. S. Atomic Energy Commission 


\section{DISCLAIMER}

This report was prepared as an account of work sponsored by an agency of the United States Government. Neither the United States Government nor any agency Thereof, nor any of their employees, makes any warranty, express or implied, or assumes any legal liability or responsibility for the accuracy, completeness, or usefulness of any information, apparatus, product, or process disclosed, or represents that its use would not infringe privately owned rights. Reference herein to any specific commercial product, process, or service by trade name, trademark, manufacturer, or otherwise does not necessarily constitute or imply its endorsement, recommendation, or favoring by the United States Government or any agency thereof. The views and opinions of authors expressed herein do not necessarily state or reflect those of the United States Government or any agency thereof. 


\section{DISCLAIMER}

Portions of this document may be illegible in electronic image products. Images are produced from the best available original document. 
TABLE OF CONTENTS

Page

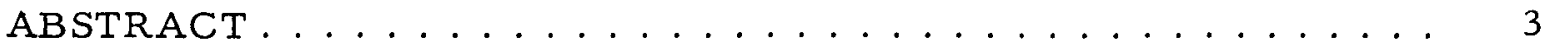

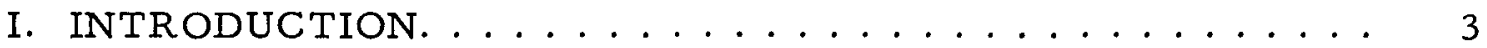

II. APPARATUS ....................... 4

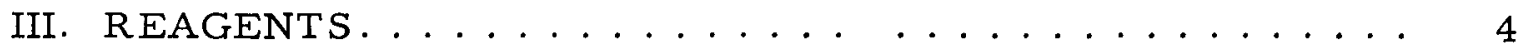

IV. SELECTION OF ANALYTICAL LINES . . . . . . . . . . 5

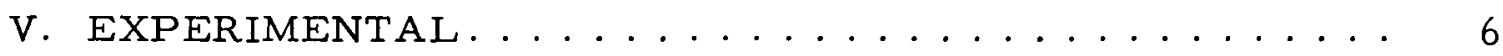

VI. ANALYTICAL ......................... 11

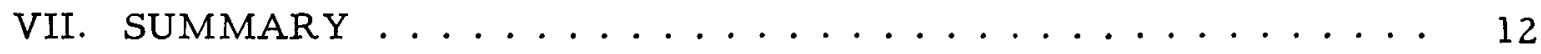

VIII. LITERATURE CITED . . . . . . . . . . . . . . 13 


\title{
APPLICATION OF THE VACUUM-CUP TECHNIQUE \\ TOWARD SPECTROCHEMICAL ANALYSIS \\ OF URANIUM-FISSIUM ALLOY
}

by

Yu Yokoyama and John P. Faris

\begin{abstract}
The vacuum-cup technique of spectrographic analysis has been studied in some detail for possible use in the analysis of uranium or uranium-plutonium alloys containing some fission product elements. The changes in spectral line intensities of molybdenum, ruthenium, rhodium, and palladium were investigated in relation to several factors such as discharge type, discharge current, form of electrode, consumption of sample solution, and consumption of electrodes.

Spectral intensities correlated with consumption of sample solution but were influenced to a large extent by the deposition of solutes on the electrode surface and to some degree by concentration of the sample solution by heat. Satisfactory working curves could be obtained by adding nickel to serve as an internal standard. For this particular application, however, the method offered no outstanding advantages over other solution techniques of spectrochemical analysis.
\end{abstract}

\section{INTRODUCTION}

The vacuum-cup electrode technique of spectrochemical analysis was introduced by Zink $(6)$ in 1959. During the excitation period the sample solution is fed from a Teflon cup up through an axial canal in a graphite electrode into the analytical gap. Both the reduced pressure in the gap and the heat of discharge contribute to the feeding mechanism, with the pumping action related to the number of breaks per half cycle of current. (6) Bass and Soulati(1) employed a vacuum-cup electrode in the analysis of plant materials. Leistner(4) studied the influence of various factors on the intensities of arsenic, boron, copper, iron, and tin in solution by employing uni-arc excitation, and reported that the sensitivity was a function of the discharge current and the amount of graphite consumed in the analytical gap. The method has shown good promise for the direct analysis of oil samples. (5) 
The use of spectrochemical methods could offer an appreciable savings of time in the analysis of complex fissium alloys because fairly lengthy chemical procedures are required for determination of the individual components. (2) In this study the vacuum-cup technique was examined in particular as a means for determination of four of the elements in a uranium matrix without prior separation. The approximate concentrations expected were molybdenum - 3.4\%, ruthenium - $2.6 \%$, rhodium - $0.5 \%$, and palladium - $0.3 \%$. All studies were with commercially available preformed electrodes.

\section{APPARATUS}

The spectrograph used for this work was a 2l-ft Jarrell-Ash Wadsworth Stigmatic Grating Spectrograph, having a linear dispersion of $5 \AA / \mathrm{mm}$ in the first order. A Jarrell-Ash Standard Varisource was employed for excitation of the spectra.

Preformed United Carbon vacuum-cup electrodes (UCP-6011) were used together with the Teflon cup (UCP-6010-A) and National Spectroscopic counter electrode (L-4036). Other types of graphite were also used in experiments to determine the optimum size, shape, and density of the counter electrode.

Spectra were recorded on Eastman Kodak SA-1 and 103-0 spectrographic plates and the spectral line intensities measured with a Jarrell-Ash Console Microphotometer.

\section{REAGENTS}

Standard solutions of molybdenum $(5.06 \mathrm{mg} / \mathrm{ml})$, ruthenium $(7.1 \mathrm{mg} /$ $\mathrm{ml})$, rhodium $(10 \mathrm{mg} / \mathrm{ml})$, palladium $(10 \mathrm{mg} / \mathrm{ml})$, cobalt $(1 \mathrm{mg} / \mathrm{ml})$ and nickel $(2 \mathrm{mg} / \mathrm{ml}$ ) were prepared. Synthetic solutions of known concentration (see Tables I and II) were made by mixing these solutions and diluting with distilled water, distilled hydrochloric acid $(6 \mathrm{M})$, or analytical grade concentrated sulfuric acid.

Table I

SYNTHETIC SOLUTIONS A

\begin{tabular}{|c|c|c|c|c|c|}
\hline & $\begin{array}{c}\mathrm{Rh} \\
(\mathrm{ppm}) \\
\end{array}$ & $\begin{array}{c}\mathrm{Pd} \\
(\mathrm{ppm}) \\
\end{array}$ & $\begin{array}{c}\mathrm{Ru} \\
\text { (ppm) } \\
\end{array}$ & $\begin{array}{c}\text { Mo } \\
\text { (ppm) } \\
\end{array}$ & $\begin{array}{l}\mathrm{HCl} \\
(\mathrm{N}) \\
\end{array}$ \\
\hline $\mathrm{Al}$ & 10 & 20 & 46.5 & 50 & 3 \\
\hline A2 & 20 & 40 & 93 & 100 & 3 \\
\hline A3 & 50 & 100 & 233 & 250 & 3 \\
\hline $\mathrm{A} 4$ & 100 & 200 & 465 & 500 & 3 \\
\hline
\end{tabular}


Table II

SYNTHETIC SOLUTIONS B

$\begin{array}{cccc}\begin{array}{c}\mathrm{Rh} \\ (\mathrm{ppm})\end{array} & \begin{array}{c}\mathrm{Ni} \\ (\mathrm{mg} / \mathrm{ml})\end{array} & \begin{array}{c}\mathrm{HCl} \\ (\mathrm{N})\end{array} \\ 8 & & \\ & 1 & 2 \\ 40 & 1 & 2 \\ 20 & 1 & 2 \\ 10 & 1 & 2\end{array}$

\section{SELECTION OF ANALYTICAL LINES}

The spectra of uranium and each element to be studied were photographed and observed. Several of the strongest lines having nearly the same excitation potentials and which were free from spectral interference are listed below in Table III.

Table III

SELECTED SPECTRAL LINES

\begin{tabular}{ccc}
$\begin{array}{c}\text { Wavelength, } \\
\AA\end{array}$ & $\begin{array}{c}\text { Excitation } \\
\text { Potential, eV }\end{array}$ & Remarks \\
\hline
\end{tabular}

\begin{tabular}{|c|c|c|c|}
\hline Mo I & 3193.97 & 3.88 & \\
\hline Mo I & 3170.35 & 3.91 & \\
\hline Mo I & 3132.59 & 3.96 & \\
\hline$R u I$ & 3728.03 & 3.32 & \\
\hline $\mathrm{Ru} \mathrm{I}$ & 3661.35 & 3.53 & \\
\hline $\mathrm{RuI}$ & 3436.74 & 3.75 & $\mathrm{U} 3436.78 \AA$ \\
\hline $\mathrm{Rh} I$ & 3692.36 & 3.35 & \multirow{3}{*}{$\begin{array}{l}\text { Pu } 3435.0 \AA \\
\text { Mo } 3434.79 \AA\end{array}$} \\
\hline Rh I & 3434.89 & 3.60 & \\
\hline $\mathrm{Rh} \mathrm{I}$ & 3396.85 & 3.64 & \\
\hline$P d ~ I$ & 3634.70 & 4.23 & \multirow{4}{*}{$\begin{array}{l}\text { Pu } 3421.34 \AA \\
\text { Pu } 3404.69 \AA \\
\text { Mo } 3404.34 \AA\end{array}$} \\
\hline Pd I & 3421.24 & 4.58 & \\
\hline $\mathrm{Pd} \mathrm{I}$ & 3404.58 & 4.46 & \\
\hline Pd I & 3242.70 & 4.64 & \\
\hline
\end{tabular}




\section{EXPERIMENTAL}

A. Excitation

Adequate intensities of the lines of the four elements to be determined were not obtained by a spark method. Excitation of these elements by ignited $\mathrm{AC}$ arc and by ignited unidirectional arc was investigated, varying the frequency of break per half-cycle and arc-power setting. It was found that an increase in frequency of break per half-cycle at a constant arc power setting caused an increase in the consumption of sample solution. This increase was accompanied by a rise in the discharge current (see Fig. 1) and resulted in a greater intensity of both the element spectra and the $\mathrm{OH}$ molecular spectra. A direct correlation between consumption of graphite electrode and discharge current was not clearly indicated (see Fig. 2).

\section{B. Counter Electrode}

In some preliminary experiments, in which National electrode L-4036 was used as the counter electrode, the consumption of graphite during a $60-\mathrm{sec}$ discharge was usually from 1 to $2 \mathrm{~mm}$, and occasionally more than $3 \mathrm{~mm}$. The discharge current decreased with increase of gap distance; for example, the discharge current was $5.8,4.7$, and $2.8 \mathrm{~A}$ at gap distances of 1,2 , and $3 \mathrm{~mm}$, respectively. This decrease of current with time was not desirable during an analytical determination. Although Leistner ${ }^{(4)}$ found some correlation between spectral line intensity and counter-electrode consumption, we found that the volume of sample solution consumed had a much greater effect and strived to minimize any change in gap distances.

UNIDIRECTIONAL ARC

\section{$\underline{A}$}

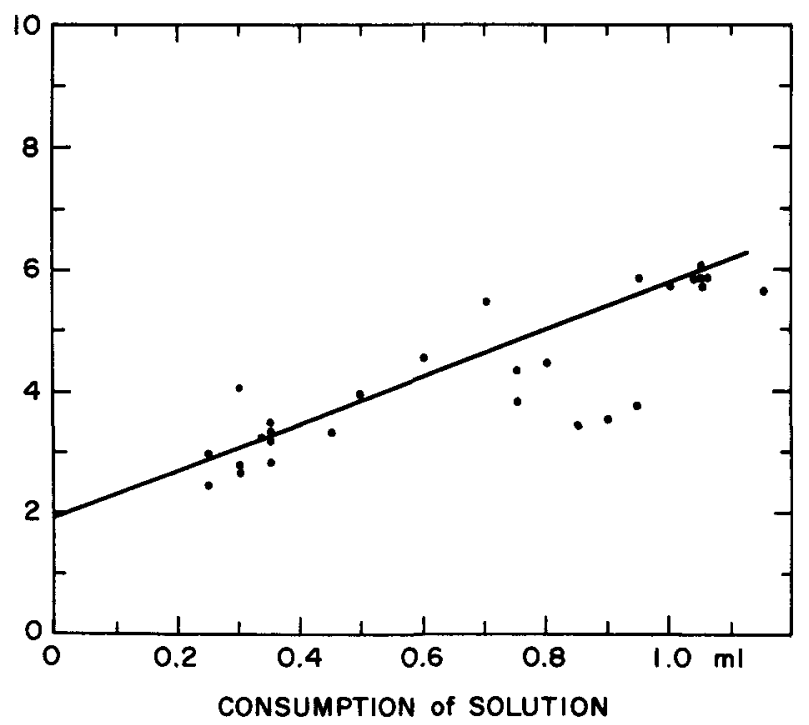

IGNITED A.C. ARC

\section{$\underline{\Delta}$}

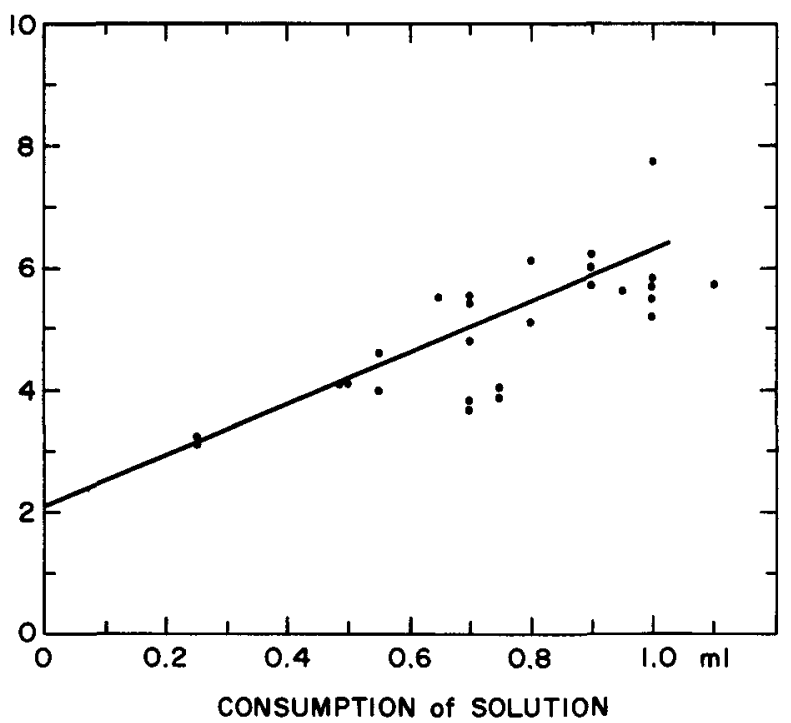

Fig. 1. Correlation between Consumption of Sample Solution and Discharge Current $(t=60 \mathrm{sec})$ 

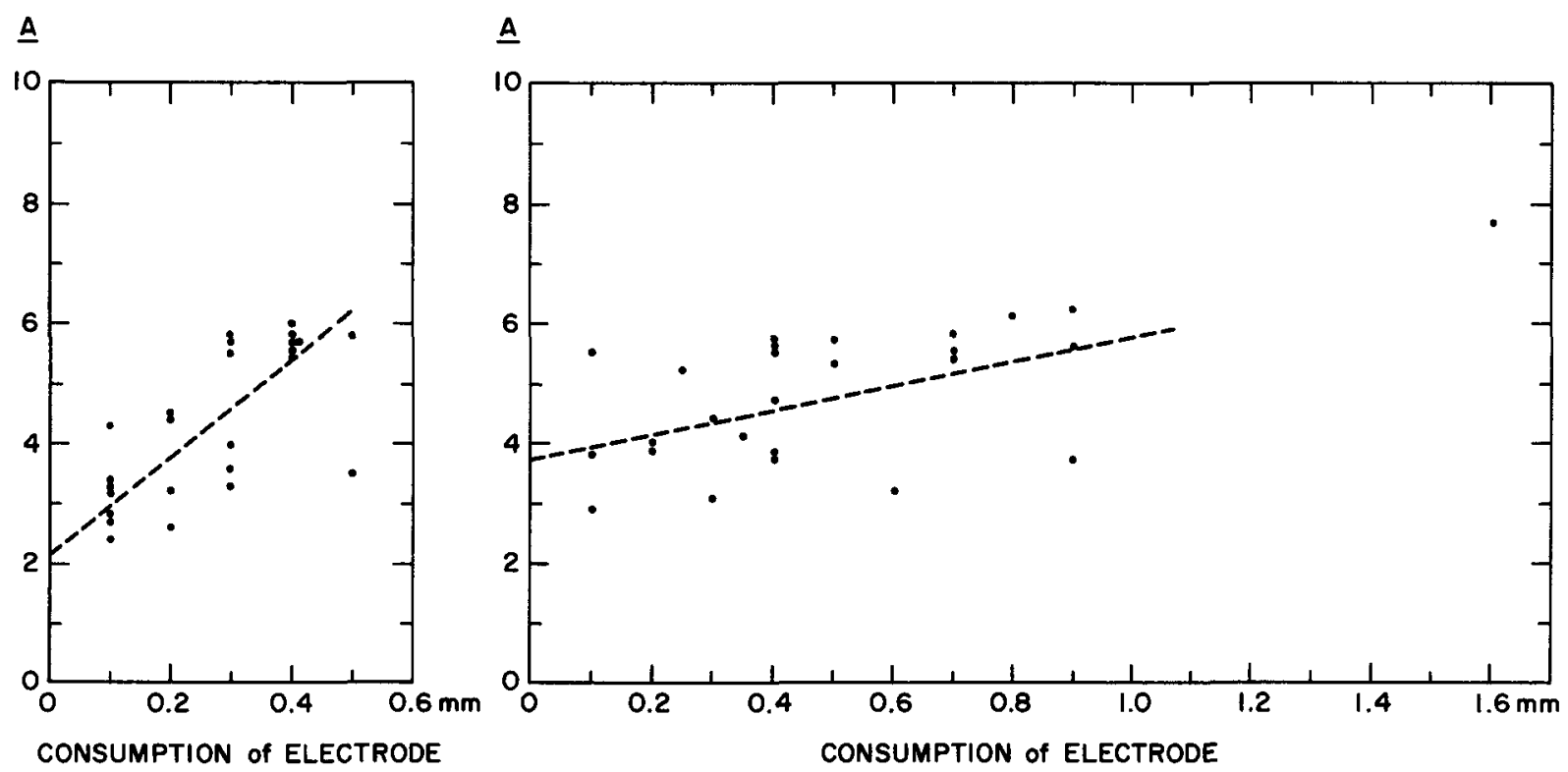

CONSUMPTION Of ELECTRODE

Fig. 2. Correlation between Consumption of Graphite Electrode and Discharge Current $(t=60 \mathrm{sec})$

Examination of electrodes with different densities and various diameters showed that the most stable discharge was obtained with a flatend counter electrode of about 3-mm diameter. No appreciable difference was found between regular and high-density graphite under the conditions used. A new graphite counter electrode was used for each discharge because the consumption rate tended to become erratic upon repeated use.

C. Comparison of Uni-arc with Ignited AC Arc

Changes in discharge current under various conditions are shown in Fig. 3, which has the same coordinates as Fig. 1. Each excitation period is represented by an arrow to show the beginning and the end of a discharge. This diagram clearly shows that the change in current of the ignited $A C$ arc was much larger than that of the uni-arc. The spectral lines of the elements excited by the uni-arc were also more intense, and the cyanogen band spectra were weaker than by ignited AC arc. The uniarc conditions were therefore selected for further study.

Several excitation conditions are represented by different types of arrows in the left-hand diagram in Fig. 3. The limited areas of the arrows for the conditions of $1-6-0$ and 2-6-10 show that the se discharge conditions are relatively stable. The scattered arrows for the 1-6-10 condition would indicate that this discharge is more unstable. 

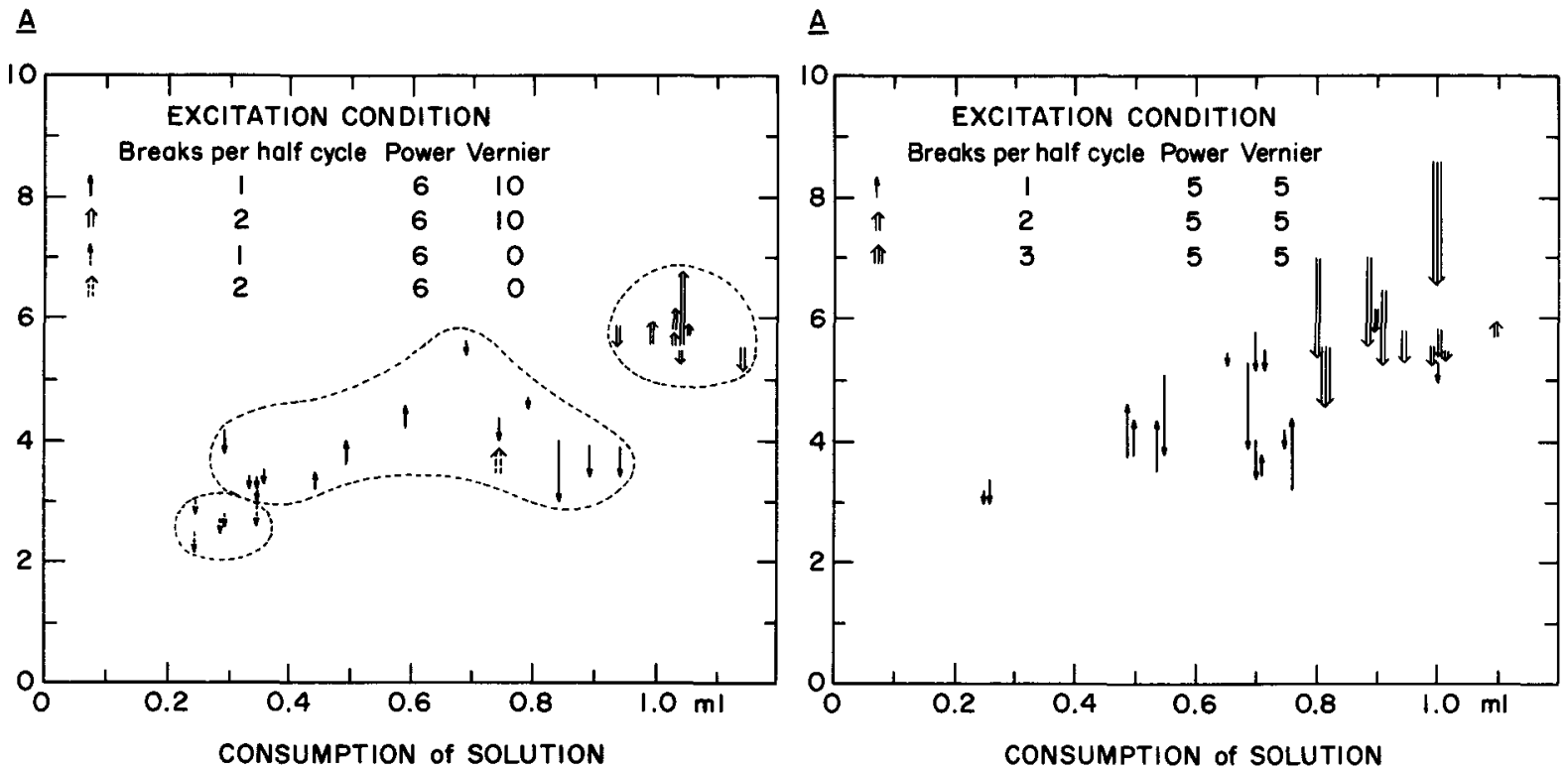

Fig. 3. Change in Current during Discharge Period (60 sec)

In the uni-arc excitation the polarity of the vacuum-cup electrode was normally positive. When the polarity was reversed, the counter electrode became very hot and rapidly vaporized. The discharge current was small, very little solution was consumed, and satisfactory results were not obtained.

\section{Variation in Spectral Intensity}

The standard solutions shown in Table I were excited under the above condition of 2-6-10 to examine the reproducibility of the spectral intensity of the four elements to be determined. In this experiment the same vacuum-cup electrode was used for four exposures of each standard, replenishing the solution in a cup after each discharge. The spectra were photographed for $60 \mathrm{sec}$ and the transmissions measured, as shown in Fig. 4. The intensities of the $\mathrm{OH}$ band component at $3361.9 \AA$, produced by excitation of water vapor, vary only within a limited range, indicating a nearly constant feed rate of solution into the analytical gap. On the other hand, line intensities of the elements in solution were low in the beginning but increased with further use of the same electrode. During the first exposure period the spectral intensities did not show linearity, but the intensities from the the second discharge lay nearly on a straight line.

Possible reasons for the difference observed between the element spectra and the $\mathrm{OH}$ band spectra could be: (1) absorption of the elements by graphite, (2) deposition of solutes on the electrodes, and (3) concentration of the sample solution by heat from the discharge. An attempt was 
made to determine the major cause by the following experiment: a standard solution containing rhodium, uranium, nickel, and cobalt was added to a vacuum-cup electrode and arc-discharge photographed for $60 \mathrm{sec}$. The remaining solution was replaced with new solution and another discharge recorded. The residual solutions were then combined, added to a new electrode, and the spectrum photographed as before. The results of these experiments are shown in Fig. 5, in which intensity ratios of the element lines with respect to the 3361.9- $\AA$ line of $\mathrm{OH}$ are given for each exposure. Element line intensities were always less for the first discharge period, even when the electrode surface was coated with Apiezon-N grease to prevent the solution from soaking into the graphite. It was concluded that the main cause of increased intensity with time was the formation of solute deposits on the electrode surface owing to heat produced from the arc discharge. Concentration of the solution could also have some effect.

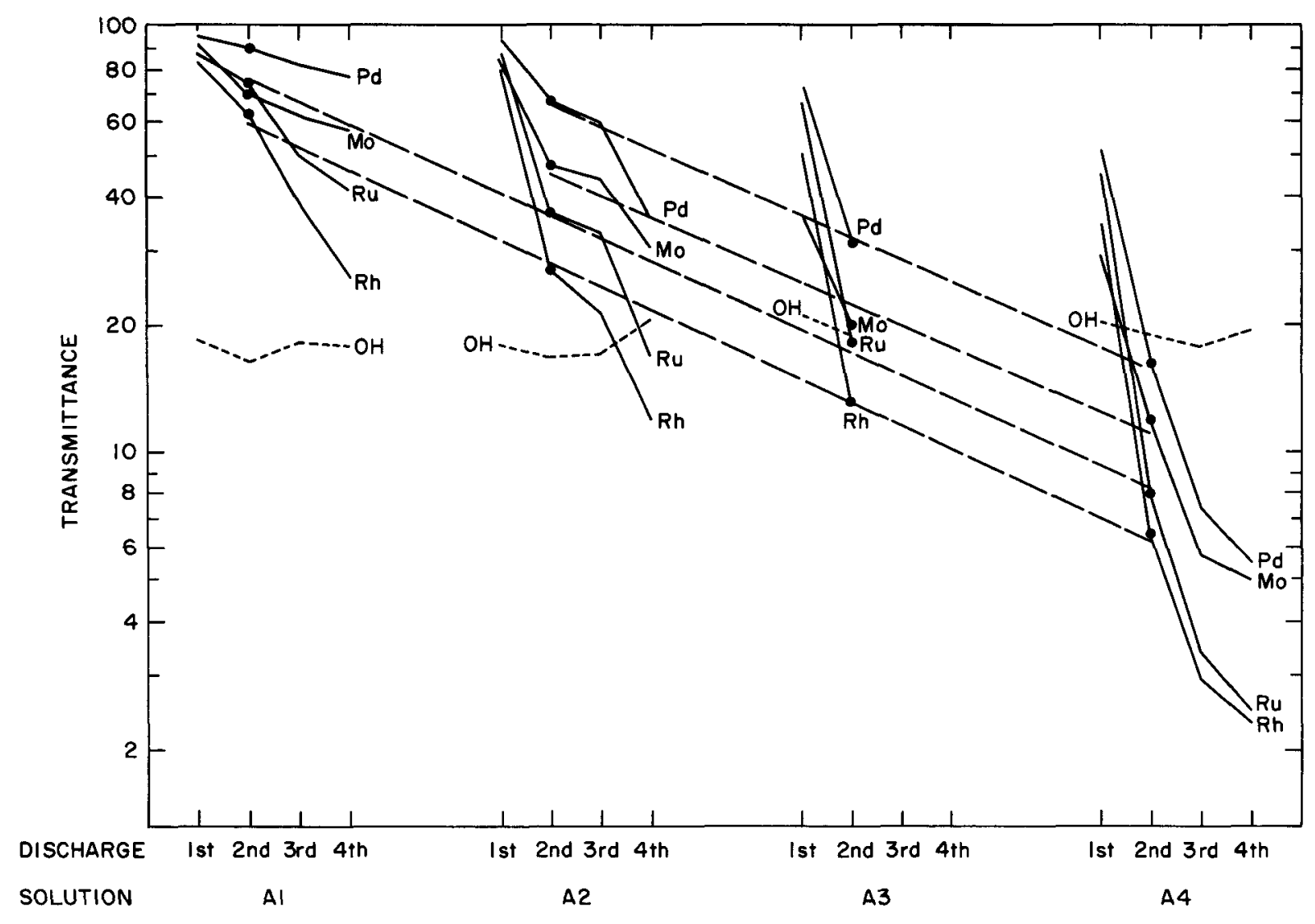

Fig. 4. Relation of Spectral Intensities with Repetition of Discharge

It has been shown in Fig. 4 that the line intensities of elements in solution tended to stabilize after an initial sparking period of $60 \mathrm{sec}$. This would indicate that neither the deposition of solutes nor their changes in concentration during axcing are an important obstacle to analytical determination by the vacuum-cup method. 


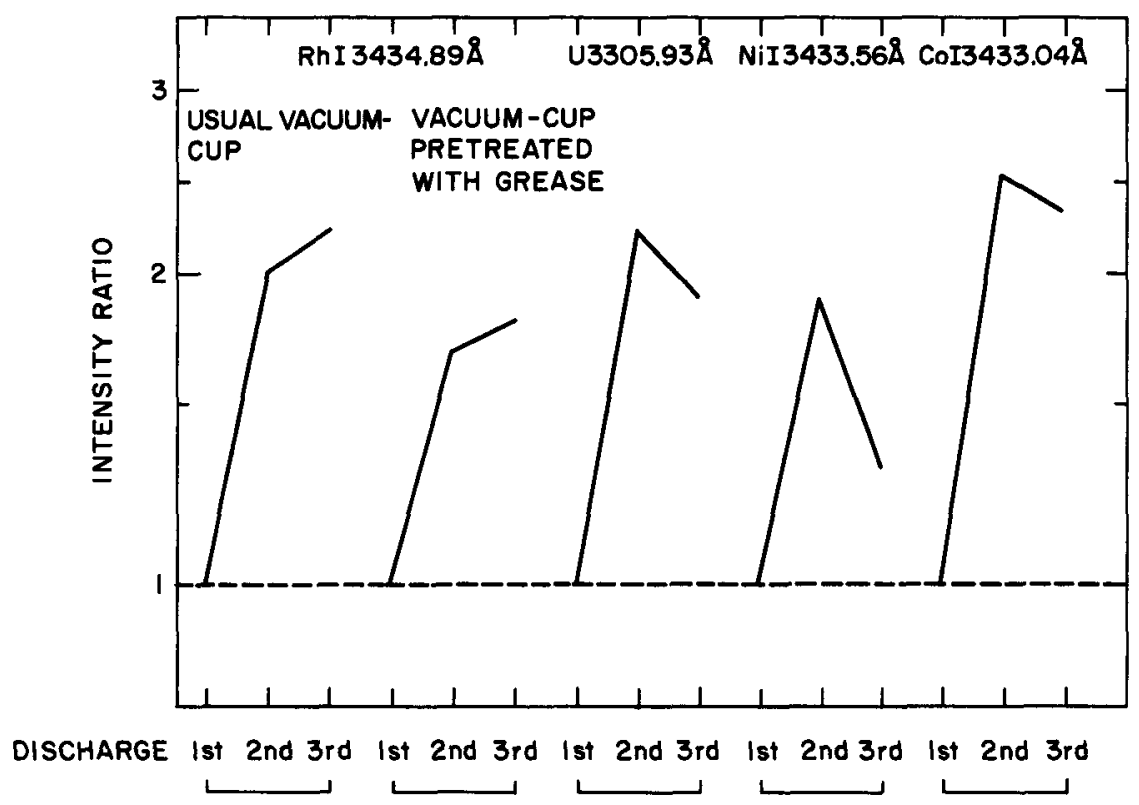

Fig. 5. Relation of Intensity Ratio with Way of Discharge

E. Selection of Acid for Sample Solution

A solution of four fissium elements was prepared in $2 \underline{N}$ sulfuric and the spectra excited under the discharge conditions used previously. Stability of the arc discharge was poor when compared with that obtained with a hydrochloric acid solution.

Corrosion of the electrode holders and other metallic parts from the solution sprayed during the excitation period was minimized by coating all exposed metal surfaces with plastic. The use of sample solutions containing nitric acid or hydrofluoric acid was avoided.

F. Amount of Uranium in Sample Solution

It was desirable for the acidic solution of the uranium-fissium alloy to be excited without any prior separation of major constituents. In order to examine the influence of uranium concentration, solutions containing $10 \mathrm{mg} / \mathrm{ml}, 3 \mathrm{mg} / \mathrm{ml}$, and $1 \mathrm{mg} / \mathrm{ml}$ of uranium were excited under the conditions described. As the uranium concentration decreased, the discharge became more stable. The discharge current was rather unsteady during excitation of the most concentrated uranium solution, consumption of sample solution was appreciably less than usual, and the background was high. During excitation of the $3-\mathrm{mg} / \mathrm{ml}$ solution the discharge was fairly stable, with the discharge current slightly lower than normal. There was no difference observed between excitation of the $1-\mathrm{mg} / \mathrm{ml}$ uranium solution and a solution containing no uranium. In both the latter cases the consumption 
of sample solution was at the normal rate. From the above experiments it was concluded that the concentration of solutes in a sample solution should not be more than $3 \mathrm{mg} / \mathrm{ml}$ for the best analytical results.

\section{ANALYTICAL}

To investigate analytical application of the vacuum-cup method, a set of synthetic solutions containing varying amounts of rhodium as a representative fissium element were prepared as shown in Table II.

Nickel was chosen to serve as the internal standard because the excitation potentials were similar and the spectrum had a number of convenient lines located in the wavelength region of the elements to be determined. The spectra were excited under the conditions used above and photographed in intervals of $20 \mathrm{sec}$. After $80 \mathrm{sec}$ the solution in a cup was replaced with a new aliquot and the run repeated. The top half of Fig. 6 shows the average change in transmittance of Rh I 3434.89 A for a duplicate series of exposures of the $80 \mathrm{r} / \mathrm{ml}$ standard solution. There was considerable scattering, as indicated by the height of the vertical lines on the diagram. The ratios obtained for transmittances of the rhodium line to that of $\mathrm{Ni}$ I $3433.56 \AA$ are plotted for the same exposures on the bottom half of Fig. 6. Although the ratios varied with exposure time, the values for each time interval showed very little scatter and the change with time followed about the same pattern for both the first and the second use of an electrode. A similar behavior was observed also for the more dilute rhodium standard solutions.

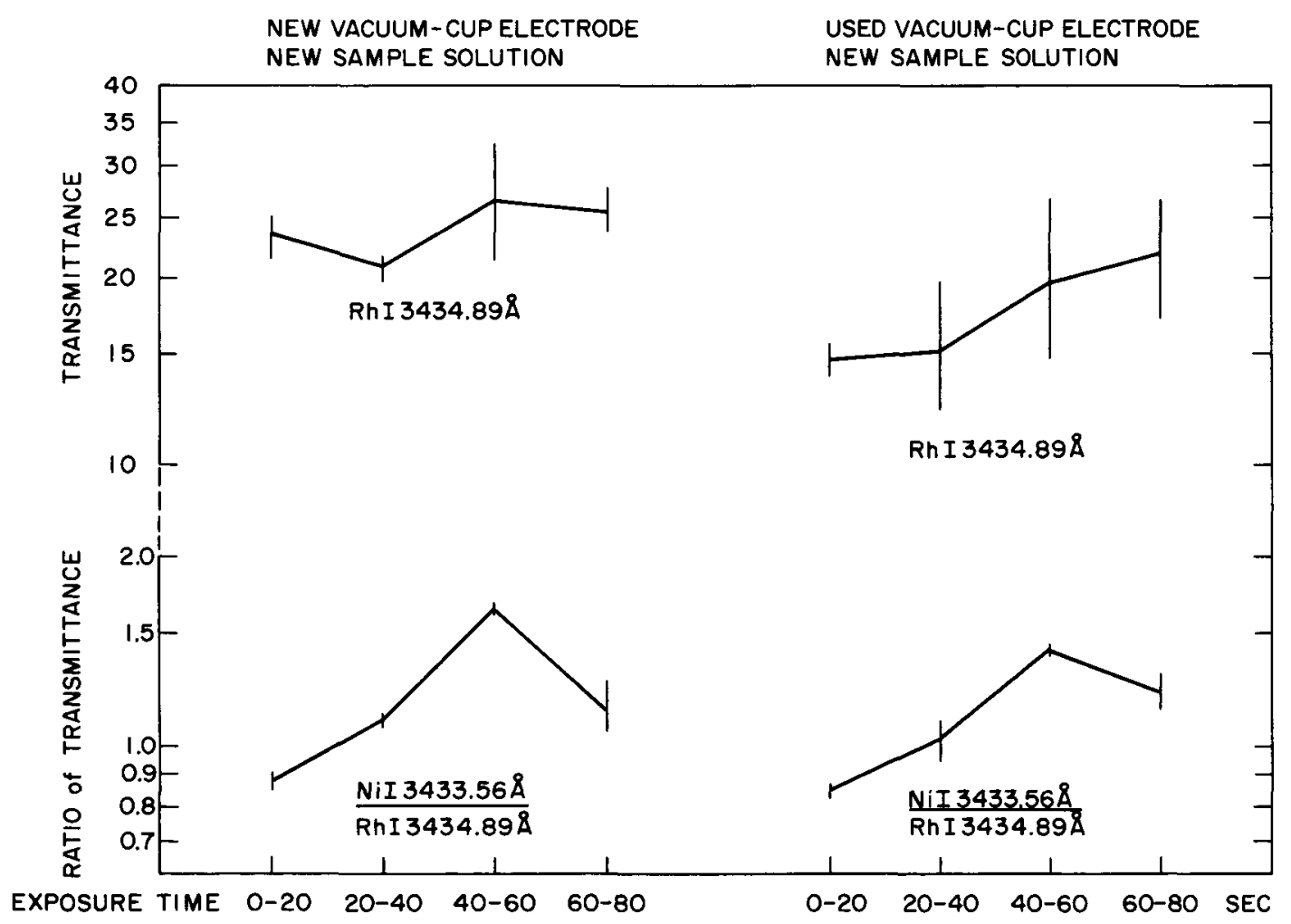

Fig. 6 Time Study of Spectral Intensity (Synthetic Solution B-1). Excitation Conditions: Igniter (Spark) $\mathrm{L}=310 \mu \mathrm{H} ; \mathrm{C}=0.005 \mu \mathrm{F} ;$ Control Gap $=5 \mathrm{~mm}$; Powerstat $=45$, Current $=2 \mathrm{~A}$. Break per Halfcycle $=2$. Uni-arc Power $=6$, Vernier $=0$, Current $=\sim 3.6 \mathrm{~A}$. 
The vacuum-cup method gave good reproducibility under constant experimental conditions, but for acceptable accuracy it was essential to photograph identical periods of sample excitation. This is further illustrated in Fig. 7 where the transmittance ratios for the standard solutions are plotted for the first period (0-20 sec) and for the third period (40-60 sec). The curves do not show linearity at the lowest concentrations because transmittance ratios were used instead of the usual intensity ratios.

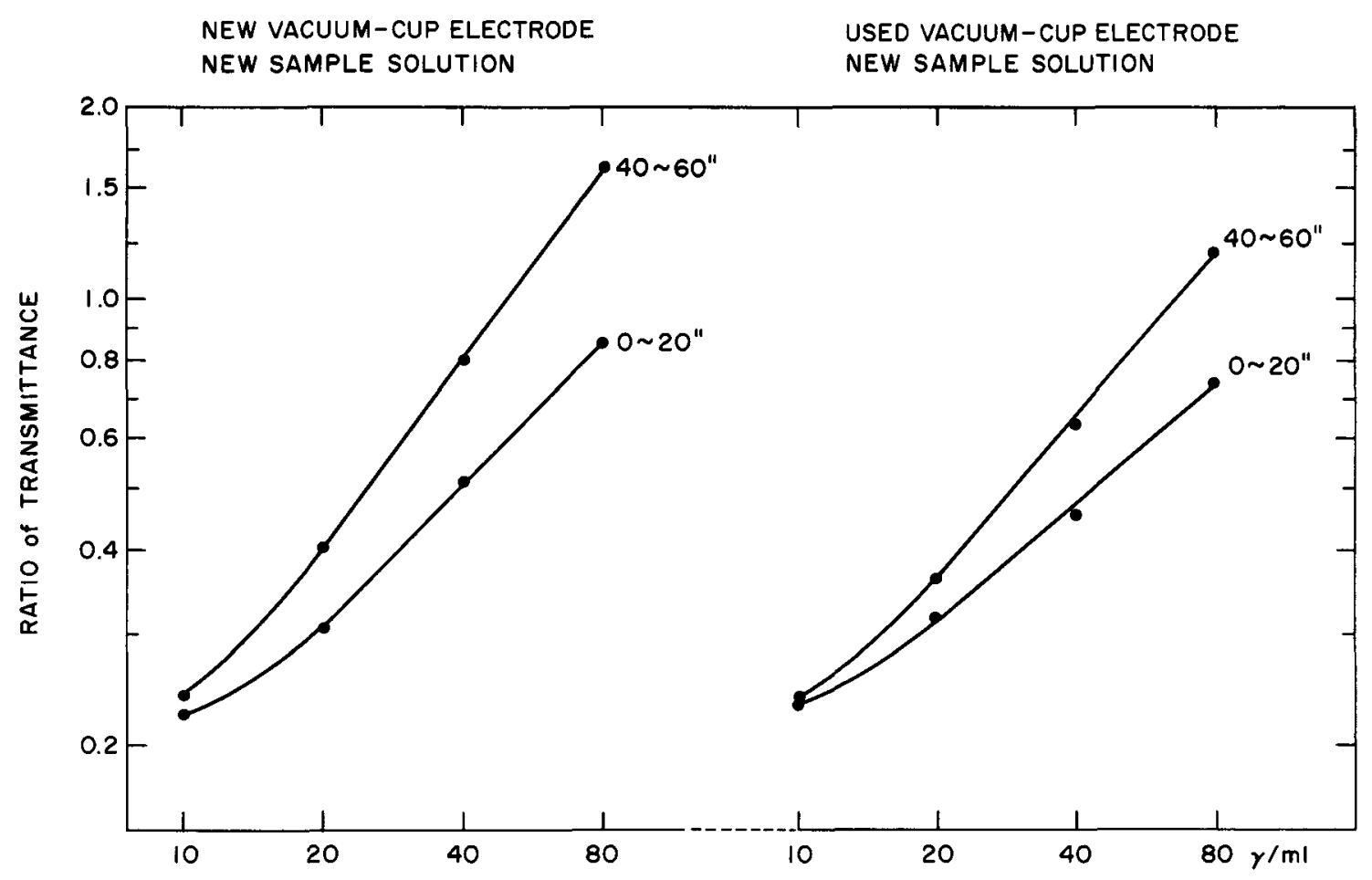

Fig. 7. Working Curve. Excitation Conditions: Same as Fig. 6

VII. SUMMARY

The above series of experiments were carried out specifically to examine the vacuum-cup method as a means for analysis of samples of complex uranium-plutonium-fissium alloys and generally to gain experience with the technique. The results have shown that satisfactory analytical values may be obtained for the fission element components of an alloy. Although a complete analytical system has not been presented, most of the information gathered should be of general value toward any application of this method of spectrochemical analysis.

The vacuum-cup method has all the inherent advantages of any solution technique of analysis, but several disadvantages should be pointed out. In addition to the parameters investigated, the results may be influenced by factors such as viscosity and density of solution, variation in electrodes - especially the axial canal diameter, and the presence of any other acids, solvents, or additives. 
During excitation the liquid sprayed the surrounding area. A Lucite enclosure with open ports was placed over the optical bench and connected to an exhaust system in order to contain the acid spray, but the condensing lens had to be cleaned often, and it was difficult to prevent corrosion of metallic parts. Excitation of highly radioactive samples would require an efficient, well-designed enclosure.

During the course of the present experiments it was demonstrated by Huff, (3) at the Argonne Fuels Technology Center analytical laboratory, that the copper spark method could be readily applied to the analysis of similar uranium-fissium alloys that also contained some plutonium. Since only small samples (ca. $50 \mathrm{\gamma}$ ) were required for an analysis, the associated radioactivity could be contained with little difficulty. Future development of the vacuum-cup technique for this particular application will depend not only on the number and type of samples received and the accuracy required, but on the analytical convenience compared with other methods of analysis.

\section{LITERATURE CITED}

1. Bass, S. T., and Soulati, J., "Use of a Vacuum Cup Electrode for Spark Emission Spectrographic Analysis of Plant Tissue, " Developments in Applied Spectroscopy, Vol. 2, p. 211, Plenum Press, New York (1963).

2. Evans, H. B., Bloomquist, C. A. A., and Hughes, J. P., Anion Exchange Separation and Spectrophotometric Determination of Microgram Quantities of Rhodium in Plutonium-Uranium-Fissium Alloys, Anal. Chem., 34, 1692(1962).

3. Huff, E. A., ANL Private Communication (1963).

4. Leistner, C. J., "Spectrographic Analysis of Aqueous Solution by the Vacuum Cup Technique," 13th Annual Mid-America Spectroscopy Symposium, Chicago (1962).

5. McGowan, R. J., Spectrochemical Analysis of Oils Using "Vacuum Cup" Electrode, Appl. Spectroscopy, 15, 179 (1961).

6. Zink, T. H., A "Vacuum Cup" Electrode for the Spectrochemical Analysis of Solutions, Appl. Spectroscopy, 13, 94 (1959). 